\title{
CFD Analysis of Scaled Wire-wrapped rod Bundle Cooled by LBE
}

\author{
Kefeng LYU ${ }^{1,3^{*}}$, Xuelei SHENG ${ }^{1,3}$, Xudan $\mathrm{MA}^{2}$, and Haitao WANG \\ ${ }^{1}$ School of Environment and Energy Engineering, Anhui jianzhu University, Anhui Hefei,230601, China \\ ${ }^{2}$ School of mechanical and electrical engineering, Anhui Jianzhu University, Hefei, China \\ ${ }^{3}$ Key Laboratory of Huizhou Architecture in Anhui Province
}

\begin{abstract}
Lead bismuth eutectic (LBE) is one of the most potential materials for coolant for Lead based reactor and Accelerator Driven Systems (ADS). Thermal-hydraulic behaviour of LBE in fuel assembly is a key issue for development of the systems. To get a deeper understanding on the complex thermal-hydraulic features of wire-wrapped rod bundle cooled by upward LBE, CFD calculation based on RANS methodologies were also performed to support the experimental results analysis. The results concluded that LBE has the similar flow resistance characteristics with traditional fluids. Both the Rehme correlation and CFD showed a good agreement with the experimental results. As for the entrance characteristics, during the fully heating length (exceeding 140 times the hydraulic diameter), the thermal field did not reach a fully developed and stable condition which is contrary to the ducted flows. Based on the experimental results and CFD investigation of heat transfer coefficient showed that the hexagonal shell has a great influence on the heat transfer coefficient in rod bundle geometry. For this reason, the application of empirical correlation should be kept cautious in rod bundle analysis.
\end{abstract}

\section{Introduction}

Accelerator Driven sub-critical Systems (ADS) are considered as one of the most potential options to incinerate long living fission products by transmutation $[1,2]$. With respect to low melting temperature, high boiling temperature, outstanding heat transfer performance, chemical stability, and good neutron economy, LeadBismuth Eutectic (LBE) is more and more attractive word wild to be both the coolant for sub-critical reactor core and spallation target in transmutation systems ${ }^{[3,4]}$.

One of the most interesting topics in thermal-hydraulic fields is the turbulent heat transfer, especially for complex geometries, e.g. fuel assemblies and high power spallation target. Owing to its lower Prandtl number, the heat transfer with heavy liquid metal is very different from the heat transfer with water or gas ${ }^{[5]}$. That is, compared to the contribution from convection, the contribution from thermal conductivity in low Prandtl number fluid like lead-bismuth eutectic is much higher than water even through at the conditions with high Reynolds number. Thus existing heat transfer numerical models and experimental experience are not directly applicable to systems cooled with liquid metal.

Moreover, due to the compact arrangement of rod bundle and the difficulties of heavy liquid metal measurement, the experimental data on the rod bundle cooled by heavy liquid metal is scare. Several experimental studies were conducted in the sixties using mercury $(\mathrm{Hg})$ and sodium-potassium alloy $(\mathrm{NaK})$, which has the similar scale Prandtl number with lead or lead bismuth. Unfortunately, as mentioned by W. Pfrang (2007) ${ }^{[6]}$, in most publications about these former experiments, no detailed description was given, whether spacer or what type of spacers have been used. Recently, with the increasing interesting in heavy liquid metal technology, a series of new bundle experiments ${ }^{[7,8]}$ were conducted to study the thermal-hydraulic characteristics of heavy liquid metal in rod bundle. Nevertheless, the rod bundle geometries have a lot of influencing factors, e.g. pitch to diameter, wire pitch, hexagonal shell and so on, only several experiments could not summarize the complex flow and heat transfer features. For the time being, it is well agreed that there still exists big deficiency in understanding and describing special thermal-hydraulic behavior in tight rod bundles, especially related to heat transfer behavior.

In order to investigate the complex thermal-hydraulic phenomena in wire-wrapped bundle and to support this type system development, a 7-heated rod bundle with helical wires with forced circulation mode was described in this paper. The flow resistances, thermal entrance characteristics, and heat transfer coefficients were investigated.

\section{Numerical setup}

The 7-heated rod bundle test section was in the vertical direction with upward flow depicted in Fig.1. The coolant LBE enters the rod bundle at the lower end and flows upward to move the heat generated by heated pins. Table 1 shows the main parameters of the experimental bundle.

\footnotetext{
" Corresponding author: 1kf2010@mail.ustc.edu.cn
} 
Each rod has a heated length of $800 \mathrm{~mm}$, and an unheated length of $1100 \mathrm{~mm}$.

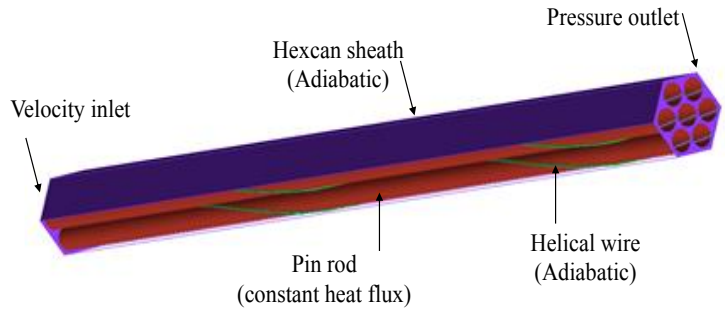

Fig. 1. CFD model and boundary conditions.

Table 1 Main characteristics of the rod bundle.

\begin{tabular}{|c|c|c|}
\hline Parameters & Symbol & Valve (mm) \\
\hline Rod outer diameter & $\mathrm{D}$ & 15 \\
\hline Pitch & $\mathrm{P}$ & 16.74 \\
\hline Rod length & $\mathrm{L}$ & 1900 \\
\hline Rod heated length & $\mathrm{Lh}$ & 800 \\
\hline Apothem & $\mathrm{a}$ & 48 \\
\hline $\begin{array}{c}\text { Helical wire } \\
\text { diameter }\end{array}$ & $\mathrm{dw}$ & 1.64 \\
\hline $\begin{array}{c}\text { Helical pitch } \\
\text { Hich }\end{array}$ & $\mathrm{H}$ & 375 \\
\hline
\end{tabular}

Three-dimensional computational fluid dynamics (CFD) based on RANS methodology was performed on the fully heated region (2.14 times the helical pitch), and the unheated region was not modeled. All the calculations were made in steady-state condition using the commercial code ANSYS FLUENT, and the k- $\varepsilon$ high Reynolds models (Standard and RNG models) were employed. Structural mesh generation is a challenge work for wire-wrapped rod bundle. For the present work unstructured grid with blending treatment between wire-wrap and fuel rod was employed. Mesh sensitivity analysis was performed to eliminate the effect of the mesh on the results. At last the number of 4.4 million control volumes was employed. Furthermore, to coherent with the high Reynolds turbulent model $y+$ values between 30 120 were set. Before starting the calculations, the boundary conditions were defined, which depicted in Fig. 1. The physical properties of the LBE coolant were given as user defined functions of temperature, which recommended by OECD/NET Hand book (2007) ${ }^{[11]}$.

\section{Results and discussion}

\subsection{Flow and temperature field}

Fig.2 and Fig.3 illustrate the velocity and temperature contours at different heights $(\mathrm{z}=525 \mathrm{~mm}, 650 \mathrm{~mm}$ and $775 \mathrm{~mm}$ ). According to the Fig. 3, it could be clearly seen that due to the different local hydraulic diameters between periphery sub-channels and inner sub-channels, the velocity and flow rate in periphery sub-channels were larger than at inner sub-channels. For this reason and the effect of adiabatic shell, the temperature distribution was non-uniform.

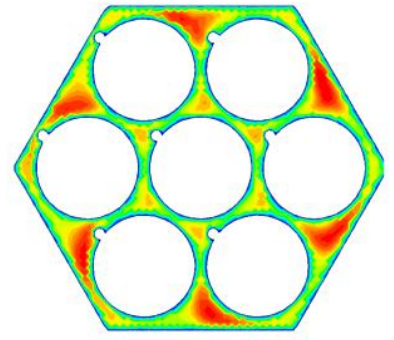

(a) $\mathrm{z}=525 \mathrm{~mm}$

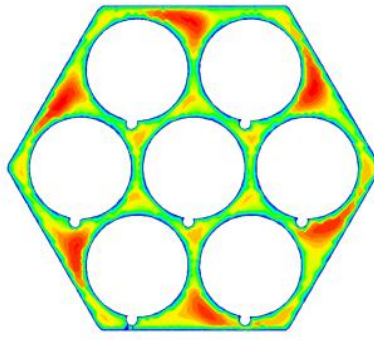

(b) $\mathrm{z}=650 \mathrm{~mm}$

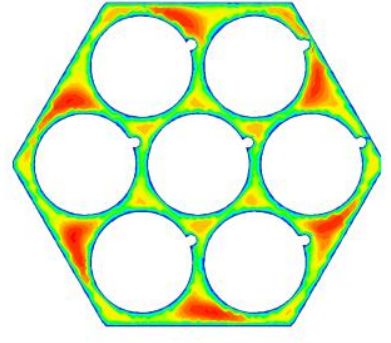

(c) $\mathrm{z}=757 \mathrm{~mm}$

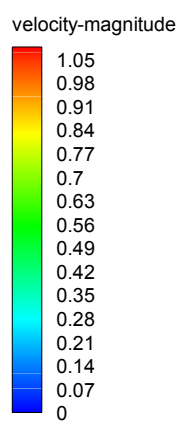

Fig.2. Velocity field in the cross section.

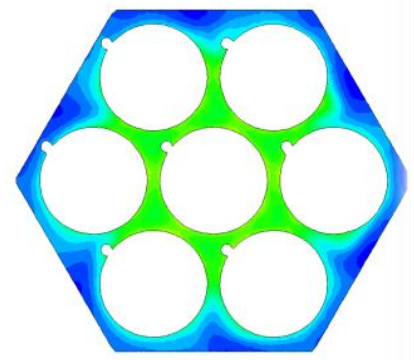

(a) $\mathrm{z}=525 \mathrm{~mm}$

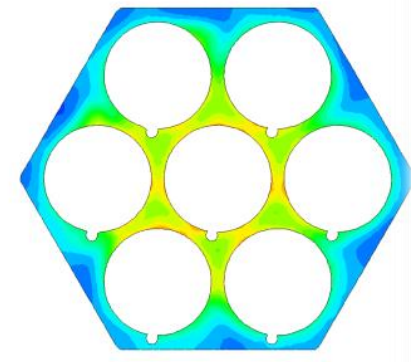

(b) $\mathrm{z}=650 \mathrm{~mm}$

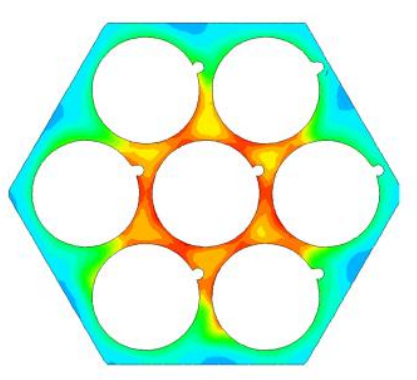

(c) $\mathrm{z}=757 \mathrm{~mm}$

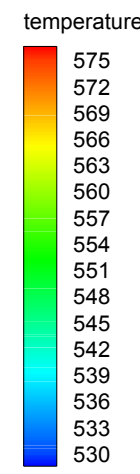

530

Fig.3. Temperature field in the cross section. 


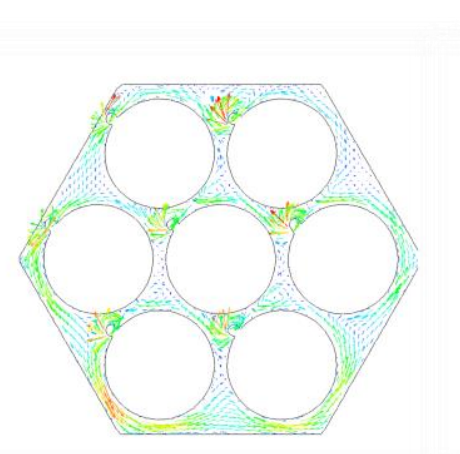

(a) $\mathrm{z}=525 \mathrm{~mm}$

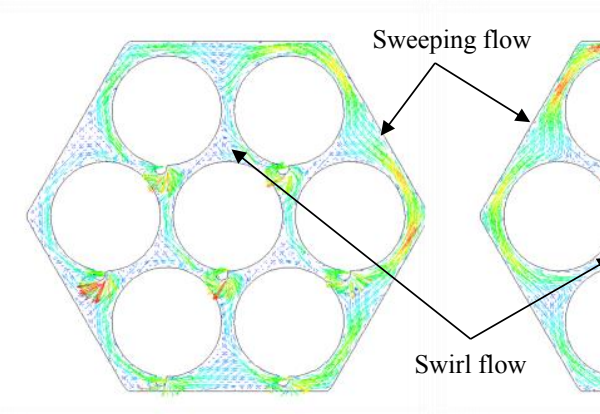

(b) $\mathrm{z}=650 \mathrm{~mm}$

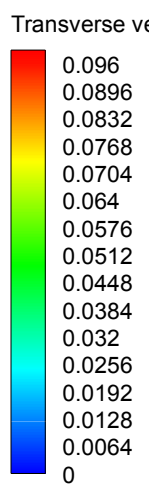

(c) $\mathrm{z}=757 \mathrm{~mm}$

Fig.4. Transverse velocity field in the cross section.

Fig.4 shows the distribution of secondary transverse velocity induced by helical wire. Two different type of secondary flow could be detected. In the edge and corner sub-channels, there were obvious sweeping flows which largely depend on the position of helical wire. While, in the interior sub-channels, the sweep flow changes its direction periodically, generating the so-called swirl flow. From the thermal hydraulic point of view, the secondary flow among the rods could prompt the temperature homogenization. However, the influence is slight compared with effect by axial velocity distribution.

\subsection{Friction factor and Nusselt profiles}

The friction factor and Nussult number by CFD predictions as function of Reynolds number are reported in Fig.5 and Fig.6 respectively. It could be seen that the variation of $\mathrm{k}-\varepsilon$ turbulent model had almost a negligible effect on the flow resistance and heat transfer results. And for the friction factor, the CFD results had a good agreement with experimental results ${ }^{[10]}$ and Rehme correlation. As for the heat transfer coefficient, the $\mathrm{Nu}$ at section $z=775 \mathrm{~mm}$ was slightly higher than the experimental values, especially for lower Pe number. And for $\mathrm{Nu}$ at section $\mathrm{z}=400 \mathrm{~mm}$, large deviations were detected at higher Pe number. The larger discrepancy is due to the smaller temperature difference between the wall and bulk temperature in high $\mathrm{Pe}$ regime. Moreover, compared with the $\mathrm{Nu}$ at section $\mathrm{z}=775 \mathrm{~mm}$, the $\mathrm{Nu}$ at section $z=400 \mathrm{~mm}$ had a relatively steep slope which had a similar tendency with experiment results. At last it should be noted that the commercial turbulent model is designed to simulate ordinary fluids like water or air, and it is usually not optimized to work with low Prandtl number fluid like liquid metal. Nevertheless, compared with the experimental results, the commercial CFD code was able to capture the general features of heavy liquid metal thermal-hydraulics.

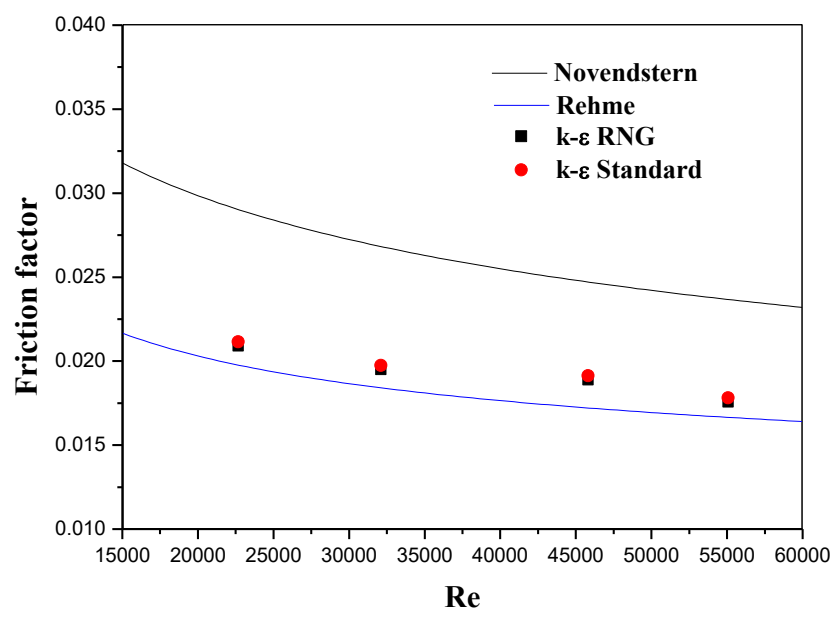

Fig.5. Friction factor by CFD calculations.

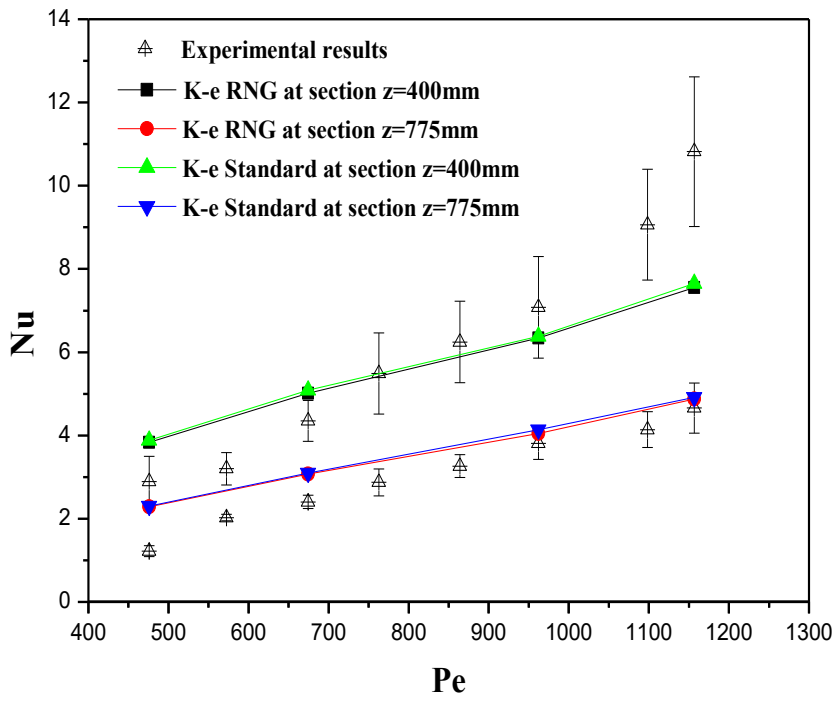

Fig.6. Local Nussult number (center rod) by CFD calculations.

\section{Summary and conclusion}

The aim of this paper is to get a deeper understanding on the complex thermal-hydraulic features of wire-wrapped rod bundle cooled by upward LBE. A bundle with 7 rods with helical wire was analyzed based on threedimensional CFD programs based on RANS methodology. The axial velocity, secondary transverse velocity and 
temperature fields were captured. And the friction factor and heat transfer by CFD calculations had a good agreement with experimental results. As can be seen the result of friction factor has a good agreement with experimental results and Rehme correlation. The comparison indicated that LBE has the similar flow resistance characteristics with traditional fluids. From the thermal field, it could be concluded that during the full heated section (exceeding 140 times the hydraulic diameter), the thermal field did not reach a fully developed and stable condition. The phenomenon was attributed to the weak communication among sub-channels in tightly packed bundle. At last, the heat transfer by CFD calculations had a good agreement with experimental results. In summary, this indicated that the commercial CFD code was able to capture the general features of heavy liquid metal heat transfer in bundle geometries. And the preliminary CFD calculations on scaled bundle were performed to get a deeper understand the LBE flow and heat transfer features in fuel assembly representative geometries.

\section{Acknowledgment}

This work is supported by Research project of anhui jianzhu university (2019QDZ07) and the Key Research and Development Special Project of Anhui province of China (201904a07020072).

\section{References}

1. C. Rubbia, Status of the Energy Amplifier Concept. Proceeding of the 2nd International Conference on Accerator-driven Transmutation Technologies and Applications, Kalmar, Sweden, June 3-7. (1996)

2. E.H. Novendstern, Turbulent flow pressure drop model for fuel rod assemblies utilizing a helical wire- wrap spacer system[J]. Nucl. Eng. Des. 22: 19-27 (1972)

3. J. Pacio, M. Daubner, F. Fellmoser, et al, Heavyliquid metal heat transfer experiment in a 19-rod bundle with grid spacers. Nucl. Eng. Des. 273, 33-46. (2014)

4. K. Rehme, Pressure drop performance of rod bundles in hexagonal arrangements. Int. J. Heat Mass Transfer 15 (12), 2499-2517. (1972)

5. K. Mikityuk, Heat transfer to liquid metal: review of data and correlations for tube bundles. Nucl. Eng. Des. 239 (4), 680-687. (2009)

6. L. Qiu, Y. Wu. B. Xiao, et al, A low Aspect Ratio Tokamak Transmutation System. Nucl Fusion. 40: 629-633. (2000)

7. M. Berthoux, T. Cadiou, The Thermal Hydraulics in a Rod Bundle Representative if the Start-up Core of the ALLEGRO Gas Cooled Fast ReactorExperimental and Numerical Approaches. Nucl. Eng. Des. 240, 3372-3386. (2010)

8. M. Tarantino, I. Di Piazza, P. Agostini, et al, Thermal-hydraulic Assessment of HLM-cooled Pin Bundle in CIRCE Pool Facility. International Conference on Fast Reactors and Related Fuel Cycles: Safe Technologies and Sustainable Scenarios FR13. Paris, France, March 4-7, 2013. (2013)

9. N. Li, Lead-alloy Coolant Technology and Materialstechnology Readiness Level Evaluation. Progress in Nuclear Energy. 50, 140-151. (2008)

10. N. Govindha Rasu, K. Velusamy, T. Sundararajan, et al, Investigations of flow and temperature field development in bare and wire-wrapped reactor fuel pin bundles cooled by sodium. (2013)

11. OECD/NEA, Handbook on Lead-Bismuth Eutectic Alloy and Lead Properties, Materials Compatibility, Thermal-Hydraulics and Technologies. 2007 edition: 15-21. (2007) 